\title{
Bibliotecas acadêmicas e o desafio da gestáo de acervos de periódicos eletrônicos: o caso da Fundaçáo Oswaldo Cruz (Fiocruz)
}

\author{
Mônica Garcia \\ Mestre em Ciências pelo Programa de Pós-Graduação em Informação e Comunicação em Saúde (PPGICS) \\ do Instituto de Comunicação e Informação e Científica e Tecnológica em Saúde (Icict)/Fundação Oswaldo \\ Cruz (Fiocruz) - Rio de Janeiro, RJ - Brasil. Coordenadora da Gestão de Acervos Bibliográficos do Icict/ \\ Fiocruz - Rio de Janeiro, RJ - Brasil. \\ http://lattes.cnpq.br/5909401174167358 \\ E-mail: monica.garcia@icict.fiocruz.br
}

\section{Cícera Henrique da Silva}

Doutora em Sciences de 1 Information Et de La Communication pela Université Paul Cézanne Aix Marseille III (AixMarseille III) - França. Pesquisadora colaboradora do Laboratório de Informação em Ciência e Tecnologia em Saúde e Professora permanente do Programa de Pós-graduação em Informação e Comunicação em Saúde do Instituto de Comunicação e Informação Científica e Tecnológica em Saúde (Icict) - Rio de Janeiro, RJ - Brasil

http://lattes.cnpq.br/5879940619015415

E-mail: cicera.henrique@icict.fiocruz.br

\section{Maria Cristina Soares Guimarães}

Doutora em Ciência da Informação pela Universidade Federal do Rio de Janeiro/convênio com o Instituto Brasileiro de Informação em Ciência e Tecnologia (UFRJ-IBICT) - Rio de Janeiro, RJ - Brasil.

Pesquisadora do Laboratório de Informação em Ciência e Tecnologia em Saúde e Professora permanente do Programa de Pós-graduação em Informação e Comunicação em Saúde do Instituto de Comunicação e Informação Científica e Tecnológica em Saúde (Icict) - Rio de Janeiro, RJ - Brasil.

http://lattes.cnpq.br/8852127703130337

E-mail: cristina.guimaraes@icict.fiocruz.br

Submetido em: 11/09/2017. Aprovado em: 07/12/2017. Publicado em: 06/05/2018.

\section{RESUMO}

A rápida evolução das TICs, bem como as mudanças no modelo da comunicação acadêmica, a crescente demanda pela gestão de dados e uma nova pedagogia do ensino superior estão afetando as expectativas dos usuários e forçando as bibliotecas acadêmicas a desenvolver novos recursos e áreas de serviço. A transição dos periódicos impressos para os eletrônicos na década de 1990 trouxe grande discussão sobre o novo modelo de contratação e gestão desta coleção nas bibliotecas. É mister, portanto, que as bibliotecas acadêmicas, particularmente aquelas em países em desenvolvimento (onde os custos de acesso à informação científica e manutenção das coleções digitais desenham um cenário desafiador), se detenham sobre que estratégias e abordagens podem assegurar a manutenção de uma coleção digital. Este artigo almeja demonstrar como as bibliotecas sofreram influência com essa transição, e particularmente como a Fiocruz tem trabalhado na formulação de um modelo de gestão de acervos, com o objetivo de gerenciar as assinaturas eletrônicas para atender às necessidades institucionais. A fim de alcançar esse objetivo, optou-se por uma abordagem metodológica qualitativa que foi realizada por dois métodos complementares: pesquisa documental e pesquisa bibliográfica. Procurou-se assim entender como tem sido tratada a questão do acesso perpétuo dos periódicos eletrônicos, tanto no âmbito nacional quanto no internacional, identificando e analisando modelos de gestão desses acervos em bibliotecas da área da saúde.

Palavras-chave: Informação científica e tecnológica. Bibliotecas universitárias. Periódicos científicos. Periódicos eletrônicos. Preservação digital. Gestão de acervos. Acesso perpétuo. 


\section{Academic libraries and the challenge of managing electronic journals collections: the case of Fundação Oswaldo Cruz (Fiocruz)}

\section{ABSTRACT}

The rapid evolution of ICTs, as well as changes in the model of academic communication, growing demand for data management, and a new pedagogy of higher education are affecting user expectations and forcing academic libraries to develop new features and service areas. The transition from print journals to electronics in the decade of 1990, brought a great deal of discussion about the new model of hiring and managing this collection in libraries. It is therefore necessary that academic libraries, particularly those in developing countries (where the costs of access to scientific information and maintenance of digital collections are a challenging scenario), should focus on what strategies and approaches can ensure the maintenance of a collection digital. This article intends to demonstrate how libraries have influenced this transition and, particularly, how Fiocruz has been working on the formulation of a collection management model, with the objective of managing electronic signatures in order to meet institutional needs. In order to reach this objective, a qualitative methodological approach was chosen that was accomplished by two complementary methods: documentary research and bibliographical research. In this way, we sought to understand how the issue of perpetual access to electronic journals has been addressed, both nationally and internationally, by identifying and analyzing management models of these collections in health libraries.

Keywords: Scientific and Technological Information. University libraries. Electronic journals. Scientific journals. Collections management. Perpetual access. Digital preservation.

\section{Bibliotecas académicas y el desafío de la gestión de acervos de revistas electrónicas: el caso de la Fundação Oswaldo Cruz (Fiocruz)}

\section{RESUMEN}

La rápida evolución de las TIC, así como los cambios en el modelo de la comunicación académica, la creciente demanda por la gestión de datos y una nueva pedagogía de la enseñanza superior están afectando las expectativas de los usuarios y forzando a las bibliotecas académicas a desarrollar nuevos recursos y áreas de servicio. La transición de los periódicos impresos a los electrónicos en la década de 1990, trajo una gran discusión sobre el nuevo modelo de contratación y gestión de esta colección en las bibliotecas. Por lo tanto, es necesario que las bibliotecas académicas, particularmente aquellas en países en desarrollo (donde los costos de acceso a la información científica y el mantenimiento de las colecciones digitales diseñan un escenario desafiante), se detengan sobre qué estrategias y enfoques pueden asegurar el mantenimiento de una colección digital. Este artículo pretende demostrar cómo las bibliotecas sufrieron influencia con esta transición y particularmente, como la Fiocruz ha trabajado en la formulación de un modelo de gestión de acervos, con el objetivo de administrar las suscripciones electrónicas para atender las necesidades institucionales. A fin de alcanzar este objetivo, se optó por un enfoque metodológico cualitativo que fue realizado por dos métodos complementarios: investigación documental e investigación bibliográfica. Se buscó de esta manera entender cómo se ha tratado la cuestión del acceso perpetuo de los periódicos electrónicos, tanto en el ámbito nacional como en el internacional, identificando y analizando modelos de gestión de estos acervos en bibliotecas del área de la salud.

Palabras clave: Información científica y tecnológica. Bibliotecas universitarias. Periódicos científicos. Periódicos electrónicos. Preservación digital. Gestión de acervos. Acceso perpetuo. 


\section{INTRODUÇÃO}

Os anos recentes trouxeram novos desafios para as bibliotecas acadêmicas (BAs). O uso intensivo de tecnologias de informação e comunicação (TICs), tanto na organização como na disseminação de informação, coloca nas BAs a responsabilidade de suprir os meios para o acesso aos recursos acadêmicos digitais, crescentemente representado pelas bases de dados referenciais e pelos serviços oferecidos das grandes casas editoriais. $\mathrm{O}$ advento e expansão do Movimento de Acesso Livre à Informação (BUDAPEST OPEN ACCESS INITIATIVE, 2002) reforça a responsabilidade das BAs, tanto em frente à instituição as quais estão vinculadas quanto aos usuários aos quais ela atende. Minimizar custos de manutenção do acervo e avançar na qualidade do atendimento e satisfação dos usuários têm transformado as BAs tanto como recurso de informação como quanto espaço físico (WOOD; WALTHER, 2000).

Saunders (2015) avança e registra que as pressóes para adaptar-se e responder às mudanças, mantendo-se relevantes, são inúmeras. A rápida evolução das TICs, bem como as mudanças no modelo da comunicação acadêmica, a crescente demanda pela gestão de dados e uma nova pedagogia do ensino superior estão afetando as expectativas dos usuários e forçando as BAs a desenvolver novos recursos e áreas de serviço. Essas mudanças, entretanto, devem sempre se equilibrar com os serviços centrais de uma BA, tais como o desenvolvimento de coleçôes.

A literatura na área de biblioteconomia e ciência da informação está repleta de artigos e relatórios que acompanham as tendências no campo das BAs, fazendo previsóes e aconselhamentos sobre como implementar planos e programas relacionados a essas tendências, incluindo as mudanças na tecnologia; na comunicação acadêmica, nos modos de acesso às coleçôes; na avaliação e na responsabilidade com direitos autorias.

Em 2006, a norte-americana Association of College and Research Libraries (ACRL) (http://www.ala.org/ $\mathrm{acrl} /$ ) listou as 10 premissas mais importantes sobre o futuro das BAs, registrando que não se tratava de previsóes, mas de mudanças que já estavam em curso.
No topo, o registro que havia ênfase crescente na digitalização das coleçóes, na preservação e na melhoria dos métodos de armazenamento e recuperação de arquivos digitais. Decorre daí a também crescente necessidade de especialização dos profissionais de informação, tanto em resposta às demandas diferenciadas dos usuários como por novo posicionamento da discussão dos direitos autorais, agora modelados pela ampliação das estratégias de acesso livre à informação científica (MULLINS et al, 2007).

Saunders (2015) faz uma síntese de estudos sobre tendências e desafios das BAs que estão orientando o desenvolvimento de novos recursos e serviços. São citados os relatórios produzidos pela ACRL nos anos 2012 e 2014, que apontam como temas emergentes o trabalho com dados abertos, incluindo curadoria deles, além dos inúmeros desafios que emergem com as questôes relacionadas ao acesso livre à informação; a importância da retenção bem como a mudança das expectativas dos usuários, consequências também de novos modelos de comunicação acadêmica. Igualmente, e não menos importante, é apontado o aumento dos preços na manutenção das coleçôes, observando que "a palavra de ordem ainda é custo" (ASSOCIATION OF COLLEGE \& RESEARCH LIBRARIES RESEARCH PLANNING AND REVIEW COMMITEE, 2013, p.2). A ACRL prevê que muitas dessas tendências exigirão que as BAs repensem a prestação de serviços, o que pode resultar em novas posiçóes e novas áreas de competências que possam implicar a recuperação de profissionais.

$\mathrm{Na}$ mesma linha, a pesquisa realizada anualmente pela Ithaka $S+R$ (http://www.sr.ithaka.org) indica que as instituiçóes-mãe das BAs normalmente as vê como desempenhando o papel central de um comprador, enquanto menos atuantes como apoio à pesquisa. Ao longo dos anos recentes, as pesquisas apontam para crescente interesse dos usuários em recursos digitais em detrimento daqueles impressos, ainda que existam diferenças entre campos disciplinares. (HOUSEWRIGHT; SCHONFELD; WULFSON, 2012; SCHWARTZ, M. 2013). 
Uma revisão sobre os planos estratégicos de $\mathrm{BAs}$ do Canadá e Estados Unidos da América (EUA) indica que, além da gestão do acervo, questóes relacionadas ao espaço e armazenamento são centrais. Igualmente as questôes orçamentárias foram identificadas como essenciais (STAINES, 2009).

Vários autores reconhecem que seria praticamente impossível oferecer uma visáo abrangente dos caminhos e tendências que têm orientado o planejamento das BAs ante as tecnologias a partir da vasta literatura científica que se debruça sobre o tema (ROSS; SENNYEY, 2008; DELANEY; BATES, 2015; GWYER, 2015). Saunders (2015) registra, entretanto, que poucos estudos têm se detido por sobre os relatórios que dáo conta do planejamento das BA, fonte valiosa para analisar como elas têm priorizado as questóes e os desafios que enfrentam.

Nesse sentido, a mesma autora foca sua análise sobre 63 planos estratégicos de BAs norteamericanas, e conclui apontando que a gestáo das coleçôes, a colaboração e a literacia informacional sáo temas que ocuparam o ponto central, seguido das questóes relacionadas ao perfil dos profissionais de informação. De fato, os desafios relacionados às coleçóes foram listados por $100 \%$ das bibliotecas pertencentes à amostra analisada. Mais, 51 dos planos estratégicos das BAs analisados $(81,0 \%)$ indicaram o acesso às coleçôes como uma prioridade. Essa questáo é tão mais importante quando se tem em foco o acesso perpétuo, aqui entendido como a garantia da posse ao conteúdo assinado após o cancelamento de uma assinatura.

O caráter central da discussão sobre o acesso perpétuo às coleçôes nas bibliotecas, quer acadêmicas ou não, ganha clareza quando se iluminam as três dimensões clássicas que definem uma biblioteca: como espaço físico, como coleçóes e como um grupo de profissionais e ferramentas organizados para promover a curadoria das coleçôes. De fato, essas dimensōes, suas tendências e desafios ante as tecnologias não podem ser analisadas de maneira separada, elas coevoluem intrinsecamente relacionadas. É nesse enquadramento que Sennyey, Ross e Mills (2009) situam que, em um ambiente predominantemente digital, essas três dimensôes ganham novos desafios: coleçôes digitais, particularmente constituídas em rede, dispensam espaços físicos, e os inúmeros e distribuídos pontos de acesso redefinem os papéis tanto dos espaços quanto dos profissionais.

Nesse cenário, a própria definição de coleção é alterada: ela está distribuída de forma ubíqua, com limites amorfos e pouco definidos, seu conteúdo é sempre mutável e sua localização física é altamente irrelevante. Caberia perguntar se um objeto digital pertence a uma coleçáo porque foi adquirido ou licenciado para uma biblioteca, ou porque está incluído em seu catálogo; ou porque está listado no sítio institucional, porque foi publicado pela biblioteca, ou porque está no servidor da mesma? Enquanto em um ambiente impresso esse pertencimento era mais facilmente definido, no digital é altamente contestável. Sennyey, Ros e Mills (2009) enfatizam que as BAs necessitam ter clareza sobre como definem sua coleção digital, e qual modelo de gestáo váo adotar. Qual o papel a ser desempenhado na gestão dessa coleção digital?

Uma coleção digital das BAs é formada, predominantemente, por periódicos científicos, que estão atrelados às grandes casas editoriais, constituindo um mercado que, pela consolidação e agregação, tem impactos significativos nos preços, nos modos de aquisição e na negociação institucional. Enquanto alguns autores sugerem que a era digital traria uma alternativa para a dependência das BAs em relação às editoras científicas (dada a autonomia de acesso à informação científica sem custos, via Web), outros consideram que isso só faria piorar (MACKENZIE, 2000; MCGUIGANGS; RUSSELL, 2008). O fato é que, no que diz respeito à perenidade de acesso às coleçóes digitais, as grandes casas editorais não fornecem qualquer garantia às instituições que, o que é considerado coleçấo digital hoje, o seja no futuro. É mister, portanto, que as BAs, particularmente aquelas em países em desenvolvimento (onde os custos de acesso à informação científica e manutenção das coleçôes digitais desenham um cenário desafiador), se detenham sobre que estratégias e abordagens podem assegurar a manutenção de uma coleção digital. 
A Gestão de Acervos Bibliográficos do Instituto de Comunicação e Informação Científica e Tecnológica em Saúde (Icict) / Fundação Oswaldo Cruz (Fiocruz), que tem como uma de suas competências assistir a direção da unidade na formulação de políticas de gestão de acervos bibliográficos e aquisição de periódicos internacionais, tomou a si a responsabilidade de se debruçar sobre a temática. No que segue, apresenta-se a Rede de bibliotecas da Fiocruz e a Gestão de Acervos Bibliográficos, que servirão de contexto para alinhar esta discussão internamente na Fiocruz.

\section{A REDE DE BIBLIOTECAS DA FIOCRUZ E A GESTÃO DE ACERVOS DE PERIÓDICOS}

A Fundação Oswaldo Cruz (Fiocruz), instituição brasileira de ensino e pesquisa na área da saúde, só obteve este nome em 1974, mas foi criada em 1900 com o nome de Instituto Soroterápico, e sempre teve desde os primórdios preocupação com seu acervo. Em 1902, com a chegada dos primeiros livros vindo na sua maioria da Europa, Oswaldo Cruz criou a Biblioteca de Manguinhos. Este acervo se mantém até hoje na seção de Obras Raras da Biblioteca.

É bem conhecida a história de seu fundador Oswaldo Cruz, contada por Bustamante

[...] de tal ordem era o interêsse e a preocupação de Oswaldo Cruz nêste sentido que, certa vez, ameaçada a Instituição de cortes de verba e preocupado êle em resolver êsse problema, alguém sugeriu [que] fôsse diminuída a dotaçáo para aquisiçôes de livros e assinaturas de revistas, ao que êle retrucou: 'Corte-se até a verba para a alimentação, mas não se sacrifique a Biblioteca'. (BUSTAMANTE, 1958, p. 11)

Com o crescimento da instituição, outras bibliotecas foram criadas com o objetivo de atender às demandas específicas das novas linhas de pesquisa. Surgiram entáo as bibliotecas da Escola Nacional de Saúde Pública e a do Instituto Fernandes Figueiras, que juntamente com a Biblioteca de Manguinhos, se vincularam em 1975 ao Centro de Apoio Técnico (Cate), subordinado à Presidência da Fiocruz.
Em 1986 foi criado o Sistema Integrado de Bibliotecas (SIBI) (Ato da Presidência no 123/88 de 15/05/88), com objetivo de reunir e disseminar os acervos bibliográficos e documentais da Fiocruz. O sistema era subordinado à Superintendência de Informação Científica e Tecnológica (Sict). Faziam parte deste sistema as três bibliotecas supracitadas e as bibliotecas dos centros regionais da Fiocruz, os Centros Regionais de Pesquisa Aggeu Magalhães, Gonçalo Muniz e René Rachou (RODRIGUES, 2005).

Durante a realizaçáo do III Encontro de Bibliotecários da Fiocruz, em setembro de 2002, foi aprovada a criaçáo da Rede de Bibliotecas da Fiocruz, incluindo, além das bibliotecas integrantes do SIBI, as bibliotecas da Casa de Oswaldo Cruz, do Instituto Nacional de Controle de Qualidade em Saúde, da Escola Politécnica Joaquim Venâncio e do Centro de Pesquisa Leônidas e Maria Deane, a última criada em 2002.

Inicialmente cada biblioteca, no período de um ano, era responsável pela coordenação da rede. Em 2006, por decisão do VI Congresso Interno da Fiocruz, a Rede de Bibliotecas da Fiocruz passou ser coordenada pelo Icict.

Fazem parte da Rede de Bibliotecas da Fiocruz as seguintes bibliotecas: Manguinhos; Saúde Pública; Saúde da Mulher e da Criança; Instituto Nacional de Controle de Qualidade em Saúde; Casa de Oswaldo Cruz; Escola Politécnica de Saúde Joaquim Venâncio; Instituto de Pesquisa Gonçalo Moniz; Instituto de Pesquisa Aggeu Magalhães; Instituto de Pesquisa René Rachou; Instituto de Pesquisa Leônidas e Maria Deane; Diretoria Regional de Brasília; Instituto de Tecnologia em Fármacos; Centro de Estudos da Saúde do Trabalhador e Ecologia Humana; Centro de Documentaçáo do Centro Latino-Americano de Estudos de Violência e Saúde.

A partir da criaçáo do Sistema Integrado (SIBI) a seleção e aquisição de periódicos passou a funcionar de forma participativa. As assinaturas eram administradas na Biblioteca de Manguinhos e atendiam às bibliotecas da rede. 
O orçamento das assinaturas vinha da Presidência da Fiocruz. Em 2006, como fruto de resoluçáo da IV Oficina de Gestão do Icict, realizada em Nova Friburgo, oficializou-se a Gestáo de Acervos Bibliográficos como responsável pela gestão de assinaturas de periódicos internacionais técnico - científicos para as bibliotecas da rede com uma proposta de negociaçáo direta com as editoras, buscando minimizar os efeitos da intermediação dos agentes. A partir desta oficina, a gestão também assumiu a preservaçáo de acervos e a contrataçáo de bases de dados e e-books.

Com a transição dos periódicos impressos para os eletrônicos, a partir da década de 1990, as instituiçôes tiveram que remodelar a gestão das assinaturas. Abriu-se grande discussão sobre Como preservar o material digital? Como garantir o acesso perpétuo à coleção assinada eletronicamente? Como disponibilizar para a comunidade científica este material?

Não distante destes problemas, a Fiocruz, que tem como premissa a preservação e guarda perpétua dos seus acervos bibliográficos no âmbito da saúde, precisou iniciar a formulação de um modelo de gestáo de acervos, com o objetivo de gerenciar as assinaturas eletrônicas a fim de atender às necessidades institucionais.

Para a inclusão de novos títulos de periódicos ou mesmo no processo de renovaçáo das assinaturas, a Gestão de Acervos se imbui da responsabilidade de orientar as bibliotecas da rede que este processo seja baseado em análise estatística de uso e também por decisóes decorrentes do Comitê de Usuários, fórum importante para as decisões sobre inclusão e exclusão de títulos.

Segundo a Política de Seleção da Rede de Bibliotecas da Fiocruz (2003), o Comitê de Usuários deverá ser formado por membros representativos da comunidade científica.

\section{DESAFIOS PARA A GESTÃO DO DESENVOLVIMENTO DE COLEÇÕES DE PERIÓDICOS ELETRÔNICOS}

Dado que o periódico eletrônico é uma realidade, há que se ressaltar algumas vantagens oferecidas por este novo formato, como:

- rápida e eficiente disseminaçáo da informaçáo: com o uso das ferramentas de divulgação de publicaçóes eletrônicas, o acesso ao conhecimento gerado se propaga com maior eficiência;

- acessibilidade aos usuários: em posse de um computador e com acesso à Internet, a visualização de um artigo não tem barreiras. Hoje este acesso vai além, permitido através de I-pad, celular e tablet;

- otimização do uso: com a opção pela assinatura de periódicos eletrônicos, que permite o acesso amplo e também a possibilidade de compartilhar informaçôes entre instituiçóes através de consórcio, busca-se minimizar os custos com assinaturas duplicadas;

- espaço físico: com a explosão da informação, as bibliotecas tiveram que enfrentar o problema de náo ter espaço para armazenar todos os documentos;

- custo das assinaturas: com a eliminação de algumas etapas do processo de produção utilizado no caso dos impressos, acreditava-se que haveria economia no preço final dos eletrônicos.

Contudo, dificuldades também começaram a aparecer, principalmente em relaçáo ao valor das assinaturas, garantia de acesso à coleção assinada após o cancelamento da assinatura e também com a gestáo dos periódicos.

Os custos das assinaturas se mantiveram altos, fazendo com que muitas bibliotecas não tivessem como manter suas coleçóes completas. $\mathrm{O}$ aumento exagerado cobrado pela assinatura dos impressos em relação aos eletrônicos se manteve nos chamados big deals, onde a assinatura de determinados títulos fica vinculada à assinatura de um pacote, mesmo que nem todos os títulos sejam de interesse da instituição. 
$\mathrm{Na}$ verdade, quando se assina um periódico eletrônico, não se está adquirindo a propriedade sobre o documento, e sim praticando um contrato de aluguel ou licenciamento de uso de um serviço por prazo determinado. $\mathrm{O}$ fato é que na maioria dos casos, quando se interrompe a assinatura, o acesso ao que foi assinado é perdido. São variadas as políticas das editoras científicas (BRIQUET DE LEMOS, 2005).

Outra questão importante a ser observada é em relação à forma de preservação de todo o material eletrônico.

Preservar os documentos nas bibliotecas sempre foi um desafio para os profissionais de informação. Com o advento dos documentos eletrônicos, este desafio passa também a ter enfoque tecnológico. Onde seráo armazenados os periódicos eletrônicos assinados? Ficarão no servidor da instituição ou em um servidor externo? $\mathrm{Ou}$ ainda, permanecerão nos sites das editoras? Assim como existem variadas questóes na decisão de assinar os periódicos científicos eletrônicos, outras existem em relação à preservação digital destes documentos.

A preservação digital se refere ao "[...] planejamento, alocação de recursos e aplicação de métodos e tecnologia para assegurar que a informação digital de valor contínuo permaneça acessível e utilizável [...]" (HEDSTROM, 1996 apud ARELLANO, 2008).

A decisão de assinar periódicos eletrônicos não pode estar desvinculada da criação de uma política de preservação digital. Nesta política devem constar todas as possibilidades de garantia de preservação dos documentos, seja pela instituição, quando existe grande estrutura tecnológica que vá garantir a permanência fiel e segura dos dados assinados, seja através da utilização dos serviços de preservação de acervo digital disponível no mercado. Porém, esta decisão não é unilateral, depende da política das editoras, que nem sempre permitem o download de toda a coleção.
Atualmente o mercado oferece alguns serviços de preservação digital, que atuam como um servidor externo, como o Portico ${ }^{1}$ e outro serviço oferecido pelos pesquisadores europeus, o Cultural, artistic and scientific knoweldge presevation, for access and retrieval - preservaçáo do conhecimento cultural, artístico e científico para o acesso e recuperaçáo. (Caspar). Algumas editoras oferecem o serviço de preservação dos documentos eletrônicos assinados com elas, seja através do acesso perpétuo ou através do pagamento de uma taxa anualmente ou pelo envio de uma mídia ao final do contrato.

\section{METODOLOGIA}

Visando buscar subsídios para a formulação de um modelo de gestão de acervo de periódicos eletrônicos, a coordenaçáo de Gestáo de Acervos Bibliográficos empreendeu pesquisa bibliográfica e documental em sua dissertação de mestrado (GARCIA, 2014).

$\mathrm{Na}$ pesquisa documental, a autora se debruçou na análise das políticas das editoras em relaçáo à garantia de acesso às coleçóes assinadas após o cancelamento das assinaturas dos periódicos eletrônicos, a partir dos sites das quatro editoras identificadas como as maiores fornecedoras de assinaturas de periódicos científicos internacionais para a Fundação Oswaldo Cruz, e complementada por meio de mensagens enviadas, através do correio eletrônico, pelos seus representantes no Brasil e também pelos representantes das duas agências que fazem o intermédio entre a Fiocruz e as editoras científicas, a Ebsco Brasil Ltda. e a ForAll Assinaturas e Livros Ltda.

A pesquisa bibliográfica foi realizada na Information Science \& Technology Abstracts - ISTA, da EBSCO e Library and Information Science Abstracts - LISA, da ProQuest, consideradas as de maior relevância para subsidiar a pesquisa, por serem especializadas na área de informação; Biblioteca Digital de Teses e Dissertaçóes (BDTD), coordenada pelo Instituto Brasileiro de Informação em Ciência e Tecnologia (IBICT), por se entender que a questáo tem afligido todo o mundo e

${ }^{1}$ www.portico.org/digital-preservation/ 
deve estar sendo discutida no âmbito dos programas de pós-graduaçáo de ciência da informação do país; na Base de Dados Referencial de Artigos de Periódicos em Ciência da Informaçáo (Brapci), organizada pela Universidade Federal do Paraná e que cobre 35 periódicos nacionais na área de informação, sendo 28 correntes e 7 coleçôes interrompidas.

\section{ANÁLISE E DISCUSSÃO DOS RESULTADOS}

Observou-se durante a pesquisa que existe uma diversidade na política praticada pelas editoras quanto ao acesso após o cancelamento da assinatura dos títulos eletrônicos, o que dificulta seriamente a gestão destas assinaturas, pois a maioria das grandes editoras náo garante acesso perpétuo ao conteúdo dos periódicos.

\section{ACESSO PERPÉTUO}

São variadas as formas de como recuperar periódicos eletrônicos com direito de acesso perpétuo. Algumas editoras permitem que a biblioteca continue acessando o conteúdo assinado através de seu servidor, utilizando todos os recursos de busca, algumas cobram uma taxa de manutenção, outras não. Existe a possibilidade de baixar o conteúdo assinado para o servidor da instituiçáo, e os dados podem vir na forma de PDF, $\mathrm{Html}$, texto, arquivo deXML ou outro formato. Outras editoras fornecem uma mídia atualizada com todo o conteúdo assinado, seja em CD-ROM, DVD, HD externo (WOLF, 2009). Para aceitar as duas últimas possibilidades, a instituição deve ter um servidor com capacidade para armazenar todo o conteúdo e ter pessoal capacitado para trabalhar a preservação digital destes conteúdos. E por uma questão de segurança deve ter uma forma de apenas os usuários autorizados acessarem aos conteúdos, pois caso contrário, pode ferir acordos tratados anteriormente com a editora, como, por exemplo, permitir o acesso apenas aos profissionais da instituição ou aos alunos de determinado programa de pós-graduação, dentre outros acordos. Somando-se a essas questôes, os dados acabam também não vindo com os recursos de pesquisa que estáo disponíveis nos sites das editoras, acarretando fragilidade na qualidade do produto oferecido.
Não se trata de um processo simples, necessita de alto grau de planejamento e conhecimento técnico.

Existem outras possibilidades quando a instituição participa do CLOCKSS, LOCKSS e Portico. Contudo, segundo Wolf (2009), ainda não se tem acesso à interface de pesquisa. LOCKSS apenas permite que faça back up dos conteúdos disponíveis no site do editor. O CLOCKSS também não funciona como um serviço de hospedagem para os acervos eletrônicos. O Portico permite acesso ao conteúdo assinado diante de situaçóes particulares da editora, como, por exemplo, no caso da editora parar de publicar o título, deixar de funcionar, não oferecer back files. $\mathrm{Na}$ verdade ele existe para assegurar a editora e náo para assegurar possíveis problemas financeiros das instituiçóes que acarretam o cancelamento de assinaturas (WOLF, 2009).

\section{LICENÇAS DE USO E ACESSO PERPÉTUO}

Em uma relaçáo entre a biblioteca e a editora deve haver maior seriedade e experiência na formulação de licenças. Muitos esforços foram feitos por uma variedade de indivíduos e organizaçóes na busca de educar as partes interessadas e para criar e promulgar as melhores práticas.

Para Hahn (2007) não existe uma licença padrão. Elas precisam refletir as necessidades de ambas as partes. Um modelo predefinido pode contribuir, mas sempre terá que sofrer adaptaçóes tanto por parte das bibliotecas como dos editores.

\section{CONSÓRCIO DE BIBLIOTECAS}

$\mathrm{Na}$ busca de solucionar esse problema, bibliotecas se uniram, criando os consórcios de bibliotecas como uma forma de incentivar a oferta de acesso a periódicos eletrônicos (PARK, 2007). Ainda segundo este autor, bibliotecas que aderem aos consórcios possuem maiores condiçôes para realizarem acordos contratuais vantajosos junto às editoras.

Bist (2005) define consórcio como uma atividade coletiva de um grupo de bibliotecas com o objetivo comum de partilhas de recursos. 
ASSINATURA POR MEIO DE BANCO DE DADOS

A assinatura por meio de banco de dados também é um recurso para proporcionar acesso aos periódicos eletrônicos. Trata-se de um modelo de contrato de locação, onde se paga para ter acesso à informação, mas não se tem a posse.

\section{ASSINATURA POR MEIO DE PACOTES AS EDITORAS (BIG DEALS)}

Este acordo é definido por Waller e Bird (2006) como um acordo para adquirir pacotes de texto completo de periódicos eletrônicos diretamente do editor dessas revistas. Este tipo de acordo é mais comum entre as bibliotecas acadêmicas. Apesar de ampliar o acesso ao maior número de títulos de periódicos, os chamados big deals são caros, incluem revistas com temáticas que náo são de interesse para a biblioteca e muitas vezes não atendem à função das bibliotecas de preservar a informação, pois dependendo da política da editora, ela não oferece o acesso perpétuo.

\section{SERVIÇO PAY PER VIEW}

Segundo Carr (2009), pay-per-view (PPV) é uma afronta ao acesso perpétuo, em que a biblioteca cria uma conta em um servidor de conteúdo para acessar os artigos, com limites de downloads, por curto prazo.

Outra forma de acordo deste serviço é a aquisição de créditos pela biblioteca que são abatidos a cada download. Estes créditos podem ser pré ou póspagos, e a biblioteca pode fazer a opção de comprar mais acessos ou arcar com os valores que excederam a quantidade estipulada.

\section{ASSINATURA EM BASE TÍTULO A TÍTULO DIRETAMENTE DA EDITORA}

Neste caso a biblioteca escolhe alguns títulos de e-journal de uma editora e paga por ele conforme termos e condiçóes acordado.
Em todos esses casos as bibliotecas precisam ficar muito atentas, e serem capazes de formular e acompanhar as licenças de acordo com as editoras. Cada vez mais o profissional responsável pelas assinaturas de periódicos eletrônicos precisa estar capacitado para a gestáo das assinaturas. Estabelecer cláusulas que garantam a continuidade da coleção, que preservem o direito de ter acesso ao que foi pago durante a vigência da assinatura. Segundo Beh e Smith (2012), os bibliotecários precisam ficar atentos e pressionar para a inclusão de cláusulas de acesso perpétuo durante a negociação da licença.

\section{CONSIDERAÇÕES FINAIS}

A preocupação com a preservação do material digital, a garantia ao acesso perpétuo à coleção assinada eletronicamente e a disponibilização desse material para a comunidade científica deve pesar na decisão pela assinatura dos periódicos.

São várias as mudanças trazidas pelo acervo digital, e com elas as bibliotecas devem reconhecer que as novas formas de acervo podem mudar as funçóes de bibliotecários e dos departamentos, especialmente os serviços técnicos. Bibliotecários são obrigados a resolver os problemas de acesso para atender às novas tecnologias (PARK, 2013).

O profissional de informação responsável pela gestão de assinaturas de periódicos precisa identificar e avaliar as variadas possibilidades de assinaturas de periódicos eletrônicos que estão disponíveis e decidir pela mais adequada para sua biblioteca ou instituição. $\mathrm{O}$ profissional precisa estar capacitado para acompanhar as mudanças, tomar decisóes quanto ao modelo de assinaturas eletrônicas, ter ciência quanto à necessidade de orçamentos para manter a dar continuidade à coleção, ser bem assessorado do ponto de vista jurídico por conta dos detalhes dos contratos, seja direitos autorais ou tipos de licença.

As políticas das editoras são variadas quanto à garantia do acesso após o cancelamento da assinatura dos títulos eletrônicos, no caso de revista que deixa de ser publicada ou é vendida ou transferida para outra editora, e também quando a editora de uma revista sai do negócio. 
No caso de big deals, as preocupaçóes devem estar voltadas para os casos de alguns títulos do pacote serem vendidos ou comprados, quando a editora de pacote de revistas sai do negócio ou é comprada total ou parcialmente por outra editora. Esta variedade de políticas gera uma dificuldade para a gestão das assinaturas, que necessita de uma política de aquisiçáo que abarque os variados contratos com as editoras. Em todos esses casos reafirma-se a necessidade das bibliotecas estarem muito atentas e serem capazes de formular e acompanhar as licenças de acordo com as editoras.

A análise dos artigos recuperados com a busca na literatura científica mostrou que os bibliotecários precisam ficar atentos e pressionar as editoras para a inclusão de cláusulas de acesso perpétuo durante a negociação de licença (BEH; SMITH, 2012) e estabelecer cláusulas que garantam a continuidade da coleçáo, que preservem o direito de ter acesso ao que foi pago durante a vigência da assinatura. A política e a missão institucional devem se refletir na licença.

Apesar dos esforços feitos por uma variedade de indivíduos e organizaçóes na busca de educar as partes interessadas e para criar e promulgar as melhores práticas, para Hahn (2007) não existe uma licença padrão. Elas precisam refletir as necessidades de ambas as partes. Um modelo predefinido pode contribuir, mas sempre terá que sofrer adaptaçóes tanto por parte das bibliotecas como dos editores.

Em uma licença devem constar pontos essenciais para contemplar um acordo justo para ambas as partes, como a forma de acesso, se será disponibilizado por meio de IP ou registro de usuários (senha e ID). É preciso definir como os editores garantem o acesso perpétuo, se serão entregues cópias de $\mathrm{CD}, \mathrm{CD}-\mathrm{ROM}$ ou uma mídia atualizada, se será disponibilizado um espaço no servidor da editora. Neste caso, se a biblioteca terá que pagar uma taxa de manutenção, se permitirá o download para o servidor da instituição ou por meio de repositórios de apoio como o LOCKSS, CLOCKSS ou Portico. Para a decisão de como será garantido o acesso perpétuo, deve estar claro se a instituição tem espaço no servidor e como será feita a preservação digital.
Ratifica-se, assim, que a decisão de assinar periódicos eletrônicos náo pode estar desvinculada da criação de uma política de preservaçáo digital. Nesta política devem constar todas as possibilidades de garantia de preservação dos documentos, seja pela instituição, quando existe uma grande estrutura tecnológica que vá garantir a permanência fiel e segura dos dados assinados, seja através da utilizaçáo dos serviços de preservação de acervo digital disponível no mercado.

As bibliotecas estáo pressionadas entre a necessidade de administrar a informação e de disponibilizar o máximo de informação para a comunidade acadêmica, muitas vezes distante. Além disso, as bibliotecas precisam se planejar com os orçamentos, muitas vezes reduzidos. Até que ponto a necessidade de preservar a informação dentro da biblioteca supera as demandas econômicas e os benefícios da distribuição on-line? São questóes que precisam estar definidas para a tomada de decisão de assinar um periódico eletrônico.

Certamente outras mudanças na disseminação das revistas eletrônicas serão inevitáveis. Neste sentido, as bibliotecas precisam ser capazes de criarem estratégias adequadas para a preservação em longo prazo do acervo eletrônico.

Este estudo permitiu a análise das políticas das editoras que forneciam os maiores números de títulos à Fiocruz, em relação à garantia de acesso às coleçóes assinadas após o cancelamento das assinaturas dos periódicos eletrônicos.

O estudo demonstrou que existe uma diversidade na política praticada pelas editoras, quanto ao acesso após o cancelamento da assinatura dos títulos eletrônicos, o que dificulta seriamente a gestão das assinaturas, pois a maioria das grandes editoras não garante acesso ao conteúdo dos periódicos. Percebeu-se uma prática diferente dos periódicos editados por associaçóes de classe, que permitem na maioria das vezes acesso ilimitado ao conteúdo dos seus periódicos, mesmo passado o período de embargo.

É constante o trabalho realizado na gestão para se adequar aos novos modelos de assinatura e também garantir a continuidade do acesso ao acervo das bibliotecas da Fiocruz. 


\section{REFERÊNCIAS}

ABRAMSON, A. Solutions for delivering digital content in the new academic enterprise. Library Hi Tech News. v.17, n. 1, 2000.

ARELLANO, M. A. M. Critérios para a preservação digital da informação científica. Brasília, 2008. Tese (Doutorado em Ciência da Informação) - Universidade de Brasília, 2008.

ASSOCIATION of College \& Research Libraries Research Planning and Review Committee, 2013. p.2. Disponível em: <http://www.ala.org/acrl/ > . Acesso em: 10 jul. 2017

BEH, E.; SMITH, J. Preserving the scholarly collection: an examination of the perpetual access clauses in the Texas A\&M University Libraries' Major e-journal licenses. Serials Review, v. 38, n. 4, p. 235-242, 2012. Disponível em: <http://www.sciencedirect.com/ science/article/pii/S0098791312001402 >. Acesso em: 10 jul. 2017.

BIST, R. S. Managing and handling electronic journals: some issues. In: CONVENTION PLANNER, 3., 2005. Proceedings... India: Assam University, 2005. Disponível em: < http://scholar. google.com.br/scholar?cluster $=5323828992398997208 \& \mathrm{hl}=\mathrm{pt}-$ BR\&as_sdt=0,5\&sciodt=0,5>. Acesso em: 10 jul. 2017.

BRIQUET DE LEMOS, A. A. Periódicos eletrônicos: problema ou solução. Disponível em: < http://www.briquetdelemos.com.br/ briquet/briquet_lemos7.htm>. Acesso em: 12 out. 2012.

BUDAPEST Open Access Initiative. 2002. Disponível em: <http:// www.budapestopenaccessinitiative.org/read >. Acesso em: 10 jul. 2017.

BUSTAMANTE, E. M. de. As Bibliotecas especializadas como fontes de orientação na pesquisa científica. Rio de Janeiro: Instituto Oswaldo Cruz, 1958.

CARR, P.L. Forcing the moment to its crisis: thoughts on pay-perview and perpetual access ideal. Against the Grain, v. 21, n. 6, p. 12-16, 2009. Disponível em: < http://docs.lib.purdue.edu/cgi/viewcontent. cgi? article $=2352 \&$ context=atg $>$. Acesso em: 10 jul. 2017.

CONNAWAY, L. S. et al. 2012 top ten trends in academic libraries: a review of the trends and issues affecting academic libraries in higher education. College and Research Libraries News, v. 73, n. 6, p. 311-320, 2012.

DELANEY, G.; BATES, J. Envisioning the academic library: a reflection on roles, relevancy and relationships. New review of academic librarianship, v. 21, n. 1, p. 30-51, 2015.

FIOCRUZ. Politica de seleção da Rede de Bibliotecas. Rio de Janeiro, 2003.

GARCIA, M. Gestão de acervos de periódicos internacionais na área da saúde subsídios para uma política de aquisição. 2014. 105f. Dissertação (Mestrado em Informação e Comunicação em Saúde) Fundação Oswaldo Cruz, Instituto de Comunicação e Informação Científica e Tecnológica em Saúde, Rio de janeiro, 2014.

Disponível em: < https://www.arca.fiocruz.br/handle/icict/14369>. Acesso em: 30 ago. 2017.
GWYER, Roisin. Identifying and exploring future trends impacting on academic libraries: a mixed methodology using journal content analysis, focus groups, and trend reports. New review of academic librarianship, v. 21, n.3, p. 269-285, 2015.

HAHN, K. L. SERU (Share Electronic Resource Understanding): opening up new possibilities for electronic resource transactions. D-Lib Magazine, v. 13, n. 11/12, 2007. Disponível em: <http:// www.dlib.org/dlib/november07/hahn/11hahn.html >. Acesso em: 10 jul. 2017.

HENRY, M. Developing capability and skills to support eresearch. Ariadne, v. 55, 2008.

HOUSEWRIGHT, R.; SCHONFELD, R. C.; WULFSON, K. Ithaka S + R US Faculty Survey 2012. New York, NY: Ithaka S + R, 2012. Disponível em: <http://www.sr.ithaka.org/sites/\%20default/ files/reports/Ithaka_SR_US_Faculty_Survey_2012_FINAL.pdf >. Acesso em 10 jul. 2017.

LEWIS, D. W. Library budgets, open access, and the future of scholarly communications: transformations in academic publishing. College and Research Library News, v. 69, n. 5, 2008.

MACKENZIE, O. J. The scientific article in the age of digitization. Dordrecht: Springer; 2007.

MCGUIGANG, S.; RUSSELL, R. D. The Business of academic publishing: a strategic analysis of the academic journal publishing industry and its impact on the future of scholarly publishing. Electronic Journal of Academic and Special Librarianship, v. 9, n. 3, 2008. Disponível em: < http://southernlibrarianship.icaap.org/ content/v09n03/mcguigan_g01.html>.

PARK, E. G. Perspective on access to electronic journals for longterm preservation. Library Collections, Acquisitions, and Technical Services, v. 31, n. 1, p. 1-11, 2007. Disponível em: < http://www. sciencedirect.com/science/article/pii/S146490550700022X>. Acesso em: 10 jul. 2017.

RODRIGUES, J. G. Rede de Bibliotecas da Fiocruz. In. CONGRESSO MUNDIAL DE INFORMAÇÃO EM SAÚDE E BIBLIOTECAS, 9., 2005, Salvador. Anais... Salvador, 2005.

CONGRESSO LATINO-AMERICANO E DO CARIBE DE INFORMAÇÃO EM CIÊNCIAS DA SAÚDE, 7., 2005, Salvador, Bahia. Anais... Salvador, 2005.

ROSS, L.; SENNYEY, P. The library is dead, long live the library! The practice of academic librarianship and the digital revolution. The Journal of Academic Librarianship, v. 34, n. 2, p. 145-152, 2008.

SAUNDERS, L. Academic libraries' strategic plans: top trends and under-recognized areas. The Journal of Academic Librarianship, v. 41, n.3, p. 285-291, 2015.

SCHWARTZ, M. Ithaka survey: Humanities faculty love the library; scientists less enthusiastic. Library Journal Online, 8 apr. 2013. Disponível em: http://lj.libraryjournal.com/ 2013/04/ academic-libraries/ithaka-survey-humanities-faculty-love-thelibraryscientists-less-enthusiastic/\#>. Acesso em: 10 jul. 2017. 
SENNYEY, P.; ROSS, L.; MILLS, C. Exploring the future of academic libraries: a definitional approach. The Journal of Academic Librarianship, v. 35, n. 3, p. 252-259, 2009.

STAINES, G. Towards an assessment of strategic credibility in academic libraries. Library Management, v. 30, p. 148-162, 2009. DOI: http://dx.doi.org/10.1108/01435120910937320

WALLER, A.; BIRD, G. We own it: dealing with perpetual access in big deals. The Serials Librarian, v. 50, n. 1-2, p. 179-196, 2006. Disponível em: <http://eprints.rclis.org/8099/1/NASIG_article_-submitted_version.pdf >. Acesso em: 10 jul. 2017.

WOLF, R. Budget crisis: a review of perpetual access. North Carolina Libraries, v. 67, 2009. Disponível em: < http://eprints. rclis.org/8099/1/NASIG_article___submitted_version.pdf >. Acesso em: 10 jul. 2017.

WOOD, P. A.; WALTHER, J. H. The Future of academic libraries: changing formats and changing delivery. The Bottom Line: Managing Library Finances, v. 13, n. 4, 2000, p. 173. 